\title{
Capacidade das células-tronco em regenerar o epitélio da pele
}

\author{
Valquíria Alice Michalczechen Lacerda' \\ Carlos Frederico Martins ${ }^{2}$
}

\section{Resumo}

A pele é o primeiro contato do corpo com o meio exterior. É responsável pela primeira linha de defesa imunológica. Quando ocorrem lesões profundas, perde a função, fica exposta a agentes infecciosos e inicia um processo lento de regeneração que pode não ser completo em função da necessidade de vários fatores de ativação. Essa dificuldade é encontrada por existir camadas diferentes (epiderme, derme e tecido subcutâneo) cujas células e composição de matriz extracelular são diferentes. As células-tronco do epitélio (queratinócitas), da medula óssea e as mesenquimais demonstram ser eficientes no processo de recuperação total da pele por meio de um enxerto proveniente de cultivo de células do próprio paciente. Entretanto, o processo de sinalização para diferenciações celulares não é totalmente conhecido.

Palavras-chaves: Pele. Lesões. Regeneração. Células-tronco.

\section{Introdução}

A pele é o primeiro contato que o corpo possui com o meio exterior. É constituída de três camadas, a epiderme, a derme e a hipoderme ou tecido subcutâneo. A epiderme é constituída de tecido epitelial, a derme de tecido conjuntivo propriamente dito e a hipoderme de tecido adiposo. Na epiderme existe a camada córnea, que é a mais externa de todas, onde as células estão mortas, com aspecto morfológico achatado (pavimentoso). Essa camada apresenta abundância em queratina, impedindo que a água evapore ou entre no organismo e altere a osmolaridade (ROSS; ROMRELL, 1993).

\footnotetext{
${ }^{1}$ Bióloga - UniCEUB. kira21bio@gmail.com

${ }^{2}$ Professor de Embriologia do Curso de Biologia - FACES/UniCEUB e Pesquisador da Embrapa Cerrados. email: carlos.frederico@cpac.embrapa.br
} 
Em muitas situações, a pele pode ser lesionada de diferentes formas, tais como queimaduras ou lesões perfurantes causando a perda de sua função. Muitos tratamentos se baseiam na substituição da região lesada (enxerto), com variados graus de eficiência. Atualmente, têm surgido novas possibilidades de correções deste tecido com a utilização das células-tronco (LI et al., 2004).

As células-tronco (CT) funcionam como um mecanismo de manutenção, diferenciando-se fisiologicamente em vários tipos de células do organismo, uma vez adultas, são conhecidas como células-tronco somáticas (CARVALHO, 2006).

As CT foram isoladas, pela primeira vez, de embriões, em 1998, pelo pesquisador James Thompson, da Universidade de Wisconsin, sendo posteriormente descartados pelas clínicas de fertilidade. Estas células foram consideradas a primeira linhagem de CT embrionárias, induzidas a se multiplicarem sem se diferenciarem in vitro. Apesar desta importante descoberta, surgiu uma enorme controvérsia da política e das religiões para a utilização ou não desta técnica, pois alegam tratar-se de seres vivos que estariam morrendo para fornecer essas células especiais (WEISS, 2005).

De acordo com Zatz (2006), as CT embrionárias são células presentes antes da fase de blástula, enquanto que Weiss (2005), afirma que as células-tronco embrionárias são encontradas no botão embrionário no estágio de blástula.

O presente trabalho tem como objetivo realizar uma revisão sobre os aspectos envolvidos na reconstituição do tecido epitelial por meio da utilização de diferentes células-tronco.

\section{A organização do tecido epitelial}

Todo tecido verdadeiro é constituído de células, matriz extracelular e fibras. O tecido epitelial é constituído de células poliédricas justapostas, existindo pouca substância extracelular. Segundo Geneser (2003), células desse tecido estão aderidas firmemente por junções intercelulares, formando folhetos que revestem o corpo, além de serem capazes de organizar as unidades secretoras do organismo. De uma maneira geral, os epitélios têm a capacidade de revestir, absorver moléculas, perceber estímulos e controlar tudo que entra ou que sai do organismo (JUNQUEIRA; CARNEIRO, 2004). 
As células desse tecido possuem várias formas e camadas, sendo determinante para sua classificação (JUNQUEIRA; CARNEIRO, 2004). A maioria dos epitélios localiza-se sobre o tecido conjuntivo formando papilas, determinando seu nome $($ epi $=$ sobre, theleo $=$ papilas $)($ GENESER, 2003).

Entre o epitélio e o tecido conjuntivo existe a lâmina basal, visualizando-se apenas em microscópio eletrônico. Ela é constituída de uma rede de fibrilas, colágeno tipo IV, glicoproteínas (laminina e entactina), proteínas ligantes como integrinas $\alpha$ e $\beta$ heterodímeros e proteoglicanas, prendendo-se ao tecido conjuntivo por fibras de ancoragem, compostas de colágeno tipo VII. Suas principais funções são: desempenhar papel estrutural, filtrar moléculas, influenciar na polaridade celular, regular a proliferação e diferenciação celular, influir no metabolismo e organizar proteínas nas membranas plasmáticas (JUNQUEIRA; CARNEIRO, 2004).

\section{Função fisiológica do tecido epitelial}

O tecido epitelial é avascular, e os que sofrem maiores tensões mecânicas possuem papilas (evaginações para aumentar a área de contato entre o tecido e a lâmina própria). Possui terminações nervosas provenientes plexos nervosos do tecido conjuntivo (JUNQUEIRA; CARNEIRO, 2004).

A camada basal é a mais profunda, onde as células estão em constante divisão mitótica para renovar o tecido que constantemente é desgastado (STEVENS; LOWE, 2000).

Os epitélios possuem funções básicas e a sua fisiologia muda de acordo com a localização. A pele que recobre o corpo é uma estrutura complexa com várias funcionalidades como a sensorial (BALDO, 1999), barreira mecânica e condutora de calor (SHAFER, 2000).

Além disso, eles podem realizar absorção como o intestino e nos rins, desde que seja especializado. As células epiteliais podem ser polarizadas em relação à propriedade de transportes, possuindo diferenças de membranas plasmáticas para as faces de camada de células e para a membrana voltada para a face oposta. Alguns tipos de junções impedem a mistura de proteínas de transporte da membrana plasmática luminal e basolateral, permitindo a troca apenas de água e íons. Isso 
garante o transporte transcelular e o paracelular. Outras substâncias como glicose, aminoácidos de polaridade neutra entram nessas células por transportadores ativos secundários, saindo então pela membrana basolateral (KUTCHAI, 2000).

\section{Bases da regeneração epitelial}

As células que irão reconstruir a parte do tecido lesado se originam do estroma ou do parênquima. Por serem diversificados e com as mais variadas funções, cada tecido possui o seu mecanismo de reparo (TORTORA; GRABOWSKI, 2002).

As células epiteliais estão em constante desgaste, possuindo capacidade de renovação, em determinadas localizações. De acordo com Junqueira e Carneiro (2004) a taxa de renovação depende de cada órgão, sendo mais rápida no intestino e lenta no fígado e no pâncreas. Células-tronco epiteliais irão repor as células lesadas, podendo ser encontradas na epiderme e no epitélio gastrintestinal por estarem em locais protegidos (TORTORA; GRABOWSKI, 2002). As mitoses de epitélio estratificado ocorrem na camada basal, onde se encontram as CT (JUNQUEIRA; CARNEIRO, 2004).

As feridas muito extensas induzem à ativação de células do estroma e do parênquima, as quais se multiplicam rapidamente para produzir fibras colágenas e fornecer resistência. Vasos sanguíneos emitem novos brotamentos para nutrir a parte regenerada, formando um tecido de granulação. Este formará um arcabouço para sustentar células epiteliais, preenchendo a área aberta e liberando um líquido bactericida. $\mathrm{O}$ reparo tecidual é dependente de fatores como a nutrição, a circulação sanguínea e a idade. Grandes quantidades de proteínas são necessárias nesta situação. Desta forma, uma adequada dieta alimentar e a circulação de oxigênio estão diretamente ligadas ao reparo do tecido (TORTORA; GRABOWSKI, 2002).

\section{As células-tronco}

As CT possuem a capacidade de se diferenciar em células de vários tecidos e regenerá-los. Podem realizar esta tarefa por serem células indiferenciadas. Elas são clonogênicas, auto-renovam-se durante a divisão mantendo a fisiologia inicial, en- 
quanto a outra se transforma em célula especializada (CARVALHO, 2001). Assim, ao se multiplicarem mantêm a quantidade de células indiferenciadas constantes (CLARKE; BECKER, 2006).

Após a fecundação do ovócito com o espermatozóide, forma-se o zigoto, o qual sofre clivagens formando blastômeros. Quando possuem em torno de 16 células estão no estágio de mórula. Logo começa a surgir uma cavidade no interior, a blastocele, devido ao aumento de fluído que separa os blastômeros em duas partes. A primeira parte é o trofoblasto, uma delgada camada celular externa que dará origem à placenta, e a segunda é o embrioblasto, um grupo de blastômeros localizados no centro e que dará origem ao embrião cujo crescimento é voltado para a blastocele (MOORE; PERSAUD, 2000).

\subsection{Tipos de células-tronco}

As CT podem ser classificadas como totipotentes, pluripotentes ou multipotentes, oligopotentes e unipotentes. As CT totipotentes estão presentes apenas no estágio anterior à blástula, por volta do quarto dia de formação do embrião, enquanto ele ainda possui de 16 a 32 células. Estas são capazes de se diferenciarem em todos os 216 tipos de tecidos do corpo humano, incluindo placenta e anexos embrionários (ZATZ, 2006).

As CT pluripotentes ou multipotentes diferenciam-se nos tecidos humanos, com exceção da placenta e anexos embrionários. Surgem quando atingem a fase de blastocisto com aproximadamente 70 a 100 células, quinto dia de desenvolvimento, e proliferam-se rapidamente. As CT oligopotentes são as que conseguem se diferenciar em poucos tecidos e podem ser encontradas no intestino. As CT unipotentes são as que conseguem se diferenciar em um único tipo de tecido, normalmente no tecido de origem (ZATZ, 2006).

As CT oligopotentes e unipotentes são consideradas CT somáticas, assim como as do cordão umbilical de um feto recém-nascido. Costumam ser denominadas de acordo com a sua origem como as CT hematopoiéticas, queratinócitas, adipócitas, mesenquimais. Essas não podem ser utilizadas em qualquer tratamento por não apresentarem a mesma plasticidade das células-tronco embrionárias (VERJOVSKY, 2006). 
As CT somáticas são encontradas em vários tecidos de crianças e adultos (ZATZ, 2004). Elas ocorrem em número reduzido, pelo fato dos tecidos já estarem bem especializados, e para isolá-las é necessária a utilização de técnicas mais precisas (LANZA; ROSENTHAL, 2004; IGUMA, 2005).

As CT embrionárias são pluripotentes, sendo capazes de gerar qualquer célula do organismo e são encontradas apenas em embriões. Há apenas 20 anos são cultivadas em laboratório e podem ser replicadas sem sofrerem diferenciação indefinidamente. Caso as condições do meio mudem, elas podem se diferenciar e não possuírem mais a capacidade de gerar um embrião (CARVALHO, 2001). Só podem ser utilizadas em tratamentos após sua diferenciação total, ou seja, não restando uma célula sequer indiferenciada no meio produzido para garantir uma correta regeneração do tecido sem causar tumores (ZAGO, 2006).

As CT normais, além do poder de auto-renovação, estão isentas do cumprimento das regras que restringem a duração da vida e a proliferação das células. Já as CT malignas possuem uma heterogeneidade de vários tipos celulares, como se fosse um órgão desorganizado (ZAGO, 2006).

As CT hematopoiéticas pluripotentes são encontradas na placenta e no cordão umbilical, podendo ser colhidas por punção. Pela técnica de criopreservação em nitrogênio líquido, estas poderão ser utilizadas no futuro como terapia celular (BOROJEVIC; BALDUINO, 2004). De acordo com Gowdak (2006), estas também podem ser encontradas na medula óssea vermelha, possuindo a capacidade de se diferenciar em granulócitos, mielóides e linfóides, com função de recuperação hematológica por meio de transplante, e em várias outras células especializadas (GOWDAK, 2006).

Já as CT mesenquimais dão origem a fibroblastos, osteócitos, condrócitos e adipócitos possuindo potencial oncogênicos (ZAGO, 2006). São conhecidas também como CT do estroma (OKAMOTO; MOREIRA-FILHO, 2004) com a capacidade de se diferenciar em células de linhagem dos tecidos conectivos, além dos já citados. Podem ser encontradas em adultos e em embriões (WU et al, 2006).

As células progenitoras somáticas multipotentes (CPSM) são encontradas na medula óssea. Assemelham-se às CT mesenquimais, mas possuem perfil fenotípico diferente como a ampla capacidade de transdiferenciação, originando células 
de linhagem ectodérmica, mesodérmica e endodérmica (OKAMOTO; MOREIRA-FILHO, 2004).

Existem também as CT germinativas primitivas que aparecem no revestimento endodérmico da parede do saco vitelino. Surgem durante a quarta semana de desenvolvimento e migram para as glândulas sexuais em desenvolvimento. Quando o deslocamento ocorre de modo indevido, essas células podem originar tumores com vários tipos de tecidos em seu interior como dente, cabelo, pedaços de osso (MOORE; PERSAUD, 2000).

Todas as CT possuem uma problemática inerente, a saber, uma eventual desregulação em seu ciclo celular, que pode originar células cancerígenas. Isso provavelmente ocorre devido ao acúmulo de mutações em alguns genes e, algumas vezes, estímulos do microambiente acontecem e promovem a reprodução desordenada dessas células (CLARKE; BECKER, 2006).

\subsection{Importância das células-tronco}

Atualmente, o excesso de embriões em clínicas de fertilidade constitui um problema. Não serão mais utilizados pelos pais, mas também não podem ser descartados, de acordo com a legislação. Muitas pessoas morrem todos os anos devido a doenças que, em futuro próximo, poderão ser tratadas com tecido provenientes de CT. Uma permissão seria o necessário, para que estes embriões se tornassem fontes de pesquisas voltadas para promover a solução de doenças ainda incuráveis (WEISS, 2005).

Um dos maiores desafios da medicina na atualidade é o de tentar estabelecer e controlar a proliferação e a diferenciação de CT para que elas possam ser utilizadas na reconstrução total de órgãos verdadeiros a partir de célulastronco do próprio paciente. Isso diminuiria as filas de espera para órgãos transplantados e promoveria melhor qualidade de vida. Não ocorreria rejeição, pois as células seriam do próprio paciente. Para isso é necessário que o conselho de ética e a justiça brasileira façam alterações para promover essas pesquisas (SEGRE, 2004).

Algumas pesquisas envolvendo tecidos já obtiveram êxito em se diferenciar a partir de CT hematopoiéticas (tecido sanguíneo). Os hemocitoblastos, que originam essas células, reconstituem o tecido lesado, principalmente o 
miocárdio. Tecidos como a medula óssea e o tecido adiposo são ótimas fontes de CT somáticas (PEREIRA, A. 2001).

Pacientes com certos tipos de câncer infantil, há alguns anos, não tinham outra saída a não ser esperar para morrer. Atualmente, a taxa de sobrevivência é de $85 \%$. Medicamentos também auxiliam em tratamentos, por exemplo, o Glivec, nos casos de leucemia mielóide crônica (CLARKE; BECKER, 2006).

Uma pesquisa realizada, em junho de 2005, mostrou um paciente com trombose arterial na perna esquerda na iminência de ter seu membro amputado - com prognóstico assegurando como certo em $90 \%$. Já havia realizado todos os tratamentos possíveis, sem sucesso algum, recebeu um transplante de CT e recuperou-se bem (BRAGA, 2005).

O pesquisador Jefferson Braga da Silva, da Pontifícia Universidade Católica do Rio Grande do Sul, realizou cirurgias para recuperar os movimentos da mão e do braço em pessoas que apresentavam lesões no nervo periférico. Foi colocado um tubo de silicone contendo CT no local de rompimento do nervo, para que as células se diferenciassem nesse tecido e recuperassem assim, os movimentos perdidos. Decorridos três a quatro meses, os resultados apareceram sem problemas de rejeição (BRAGA, 2005).

Algumas doenças, como diabetes do tipo I, aumentaram na população. Apesar das dificuldades de transformar CT em células das ilhotas pancreáticas, os primeiros resultados mostram que futuramente será possível substituir as células danificadas, eliminando a necessidade da medicação utilizada atualmente (MANOELI, 2006).

Uma outra doença que mais causa mortalidade no mundo é o infarto no miocárdio. $\mathrm{O}$ corpo tenta reparar o tecido que morreu, mas não o substitui com atividade fisiológica cardíaca, pois os miócitos não se dividem. As CT hematopoiéticas recebem comando genético por proteínas específicas, transformam-se em cardiomiócitos e recuperam o miocárdio e o bombeamento sanguíneo. Vários pacientes obtiveram sucesso com essa técnica, não necessitando mais de um transplante de coração (FRANCO, 2006).

Existe a possibilidade de pessoas receberem células-tronco de outras pessoas, ou seja, CT heterólogas. O grande problema está relacionado à rejeição imu- 
nológica (CARVALHO, 2006). Além disso, as CT podem ser utilizadas para testar novos fármacos, toxinas e cosméticos, sendo vetores para a terapia gênica (OKAMOTO; MOREIRA-FILHO, 2004).

Um outro método consiste em transferência nuclear de células somática (TNCS), uma alternativa para curar doenças com segurança. O paciente é o seu próprio doador, não havendo rejeição do corpo depois do transplante. Porém, não atende a todas as expectativas por não curar doenças de origem gênica (PEREIRA, L., 2006).

\subsection{Bases da diferenciação celular}

Sinais químicos, fatores de diferenciações e outras substâncias como a matriz extracelular são responsáveis em diferenciar as CT em outros tipos celulares (OKAMOTO; MOREIRA-FILHO, 2004).

As CT embrionárias podem se multiplicar (ABREU; ALMEIDA 2006), in vitro, por mais de trezentas passagens em cultura. Proteínas como a OCT-4 (fator de transcrição) e a enzima telomerase garantem o fenótipo pluripotente e imortal dessas células. Já as CT somáticas possuem capacidade de expansão in vitro limitada. As citocinas IL-3, IL-6 (Interleucinas 3 e 6), os fatores de crescimento como o SCF (fator de CT) e o GM-CSF (fator estimulante de colônias de macrófagos e granulócitos) auxiliam na expansão celular, atingindo 60 vezes o volume celular. No entanto, as CT hematopoiéticas não se multiplicam muito nessas condições por estarem diferenciadas. Já as células-tronco hematopoéticas $(\mathrm{CTH})$ do cordão umbilical podem ser mantidas por até seis meses nestas condições, onde FL (FLT3 ligante) e TPO (tromboproteína) no meio garantem as células progenitoras e o $\mathrm{CD}_{3} 4^{+} \mathrm{em}$ mais de duzentas vezes o número de células iniciais, com quase nenhuma diferenciação (OKAMOTO; MOREIRA-FILHO, 2004).

A capacidade de proliferar-se está ligada à integridade dos cromossomos. Os telômeros (TTAGGG) repetidos em tandem presentes na extremidade dos cromossomos protegem-no da degradação. Toda vez que a célula se replica perde parte dos telômeros causando instabilidade do genoma, disfunção celular, limitação 
de proliferação ou apoptose. A telomerase é um complexo ribonucleoproteico no DNA, cujo gene competente é o TERT. Sua produção é induzida por citosinas e inibida por proliferação celular. A diminuição dos telômeros pode ser revertida pelo G-CSF (fator estimulante de colônia de granulócitos), aumentando em 10 vezes a produção de telomerase em células $\mathrm{CD}^{+} 4^{+}$in vivo (OKAMOTO; MOREIRAFILHO, 2004).

Em relação à epigenética, os embriões bovinos, fertilizados in vitro, as células são consideradas não metiladas por apresentar apenas $9 \%$ de metilação em seu genoma, enquanto que nos embriões produzidos por transferência nuclear, suas células são metiladas (65\%do genoma metilado), assemelhando-se muito com as células doadoras de núcleo (72\%de metilação no genoma). De acordo com Kang e colaboradores (2001), no desenvolvimento embrionário natural, quando o embrião possui de quatro a oito células, elas possuem 14 \% das regiões genômicas metiladas; no estágio de mórula possuem 6\% de metilação genômica e no estágio de blastocisto são consideradas não metiladas para sofrerem reprogramação (KANG et al, 2001) e ativar os genes do novo indivíduo (LIANG et al, 2002).

A marca epigenética é uma mistura protéica e química que envolve, sustenta e adere ao DNA, operando por código, até hoje oculto. Estas marcas podem ser armazenadas, apagadas e reescritas ao longo da vida do indivíduo (GIBBS, 2003).

As CT pluripotentes precisam ter seu extenso genoma desmetidado, as metilações gameta-específico parentais herdadas, para que seu desenvolvimento seja bem estabelecido. Na transferência nuclear de células somáticas (TNCS), essa reprogramação foge dos padrões e afeta a sobrevivência desse indivíduo (KANG et al, 2001).

Os fragmentos de DNA são metilados para se manterem inativos. De acordo com a Gibbs (2004), engenheiros genéticos realizaram um estudo onde uma enzima responsável pela metilação das células-tronco embrionárias foi inativada. Com isso os fragmentos que antes não eram expressos tornaram-se ativos e causaram uma freqüência de mutação dez vezes maior que o normal. Conclui-se então na possível aceleração de cânceres quando fatores anormais epigenéticos ocorrem, já que tumores quase não apresentam metilação no genoma de suas células (GIBBS, 2003). 
Os mesmos mecanismos de sinalização são usados por células normais e tumorais. De acordo com Okamoto e Moreira-Filho (2004), essas células expressam grande quantidade de telomerase.

A utilização de IGF-1 (fator de crescimento semelhante à insulina) pode convocar a sinalização das CT a partir de outros tecidos para a região lesada, ou fazer com que as células do tecido original se diferenciem no tecido desejado (LANZA; ROSENTHAL, 2004).

As CT malignas descendem de CT ou de células imaturas, que passaram por uma transformação maligna. Pesquisas em mecanismo de regulação de CT normais revelaram uma organização hierárquica de células de um tumor, e que essas se disfarçam de CT normais (BELLINGHINI, 2005). As CT normais possuem uma regulação genética rigorosa, quando isso foge do controle forma um tumor maligno. Além disso, essas células malignas podem migrar para outras partes do corpo (CLARKE; BECKER, 2006).

Normalmente, as CT não migram de um tecido para outro, mas podem se deslocar com células guardiãs para influenciar em sua diferenciação e impedir que fatores externos afetem sua transformação. Por isso, nem todas as CT malignas são capazes de gerar tumores em um novo microambiente, mas sob certas condições, uma CT normal pode gerar um tumor. Estudos futuros terão como alvo as CT cancerígenas reprodutivas que podem ser induzidas a morrer, enquanto as não proliferativas morrerão por si mesmas (CLARKE; BECKER, 2006).

\section{Utilização das C.T. para diferenciação em células epiteliais da pele.}

\subsection{Células-tronco queratinócitas}

Há 40 anos, surgiu a idéia de cultivar queratinócitos para utilizá-los como enxerto de pele, baseando-se na observação de crescimento dessas células em sistema in vitro, um cultivo expansivo de multicamadas remanescentes da epiderme. Graças à habilidade de cultivá-las para formar um órgão parecido com o epitélio in vivo, é possível realizar a transferência de folhas celulares para recipientes. $\mathrm{O}$ cultivo em larga escala foi iniciado por Greend e colaboradores em 1975 e o poder 
de fornecer grandes amostras de epiderme autóloga foi testado em 1984, quando dois pacientes pediátricos queimados receberam enxerto que cobria $49 \%$ e $54 \%$ da área superficial do corpo (LANGDON, 1989).

Em queimaduras muito espessas a regeneração da epiderme não é espontânea, pois as estruturas da derme também são afetadas. A incidência, em longo prazo, de lesões de grande profundidade acontece devido à cicatrização e contratibilidade dos danos que a derme sofreu. Vários testes foram realizados para sintetizar um enxerto de pele para recobrir as duas camadas até que, Cuono e colaboradores, em 1986, conseguiram por meio da derme, supostamente morta, realizar um enxerto halogênico que suportou culturas de queratinócitos, comprovando a nova epiderme. A reconstituição da pele incluiu melanócitos funcionais. De acordo com (Landong et al, 1989), a área que recebe enxerto consegue unir-se à área afetada em um período de três semanas sem sinais de rejeição, deixando uma pequena cicatriz que pode desaparecer.

A importância da técnica é a avaliação de potencialidade do enxerto. $\mathrm{Pa}$ cientes imunocompetentes, nas partes mais espessas, a cultura pode não ser permanente e preferivelmente são substituídas gradualmente por queratinócitos autólogos (LANGDON, 1989). Antigamente ocorria falta de autoenxertos convencionais da pele, pois a mesma era limitada a pacientes com queimaduras severas. Entretanto, já existem métodos capazes de cobrir quase toda a superfície corporal (LANGDON, 1989).

A epiderme de mamíferos possui uma proliferação celular acelerada quando ocorrem queimaduras e ferimentos. As responsáveis por isso não são facilmente distinguíveis das outras células, mas existem estudos para caracterização de CT do epitélio de camundongos e em humanos (LANGDON, 1989).

As culturas de queratinócitos ocorrem pelas células alimentadoras da derme, os fibroblastos. Esses são cultivados, facilmente, pois não necessitam de diferenciação para serem mantidas em laboratório. Na presença de fator de crescimento de epiderme (EGF) ou fator de transformação de crescimento $a$ (TGF $\alpha$ ), queratinócitos humanos podem expandir-se em uma taxa de 1:1016. Em cuidadosa análise desse potencial, foram revelados três tipos de células básicas para o tamanho dos 'clones' que eles são capazes de gerar: holoclones, que possuem grande 
potencial de proliferação contendo células que sempre irão formar colônias de passagem (95\%); meroclones, com potencial proliferativo intermediário e, paraclones, que "abortam" e diferenciam-se após algumas passagens. Apenas holoclones possuem a plasticidade de se transformar em outros tipos celulares (ALONSO; FUCHS, 2003).

Como não existem evidências morfológicas para diferenciar as CT da epiderme das que as circundam, os cientistas utilizam um análogo de nucleotídeo (bromocleoxiuridina) para estudar as características bioquímicas e funcionais dessas células importantes. As CT hematopoiéticas possuem vários marcadores superficiais que indicam o seu tipo. Em CT queratinócitas esses marcadores ainda não são conhecidos. Contudo, essas células podem ser identificadas in vivo por retenção de marca ou por clonogenicidade in vitro (ALONSO; FUCHS, 2003).

Um ou outro método permite fácil isolamento de CT para análise, mas ainda se necessitam marcadores para as CT epidérmicas. Um dos candidatos a marcador é um receptor transmembrânico de família das integrinas, cujos membros são responsáveis pela fixação de camada basal da epiderme na membrana basal. As células queratinócitas apresentam altos níveis de integrina- $\beta 1$ em suas superfícies, qualidade hemidesmossomal $\alpha-6$ (que se associa com $\beta-4$ para forte junção entre a membrana basal e laminina-5). Algumas dessas características permitem um potencial proliferativo de qualidade para adesão em integrina- $\beta 1$, associada à pro-minuciosa com $a-2$ (colágeno tipo IV), a-3 (laminina-5), a-5 (fibronectina) e a-9 (tenascina) em queratinócitos (ALONSO; FUCHS, 2003).

Os níveis de expressão de integrina podem mudar quando são transferidos da pele viva para meio de cultura. As culturas eficientes de queratinócitos humanos obtêm uma rápida adesão com colágeno tipo IV, característica de células com elevadas taxas de integrinas a-2. Algumas pesquisas relatam que moléculas como a protooncogênese c-myc são necessárias na transformação de CT em células de trânsito-amplificação. Esta molécula é uma reguladora transcricional de proliferação em vários tipos de células. Os níveis dessa substância não influenciam apenas nesse tipo de decisão nas CT filhas, como também na decisão de que linhagem adotar. Outro fator é o p63, um homólogo do p53. Sabe-se que ele é expresso no limbo córneo in vivo e em culturas de holoclones de queratinócitos in vitro, ainda não tendo sua fisiologia bem compreendida (ALONSO; FUCHS, 2003). 
As aplicações clínicas de CT do epitélio ocorrem por meio de enxerto de queratinócitos cultivados, previamente coletados e posteriormente reimplantados no próprio paciente no local danificado. Esse método é efetivo, porém limitado pela avaliação de área superficial limitada da pele e pela capacidade de originar algum grau de injúria adicional. A utilização requer pequenas áreas de coleta e permite cobrir grandes áreas superficiais. A dificuldade da utilização dessa técnica é o tempo necessário para o crescimento do epitélio in vitro, pois o paciente fica suscetível a infecções, e a folha epitelial produzida, por ser frágil, pode não aderir em algumas regiões. O desenvolvimento abaixo da pele enxertada pode assegurar a expansão dos queratinócitos. Essa técnica pode ser utilizada como fonte de instrumento de terapia gênica (ALONSO; FUCHS, 2003).

\subsection{Células-tronco da medula óssea}

Recentes descobertas sugerem que na ausência de injúrias, enxertos de células derivadas da medula conseguem, em baixos níveis, se diferenciar em células epiteliais in vivo, no sistema gastrotestinal e na pele. Ainda não foi desvendado se o processo ocorre devido à transdiferenciação de CTH ou se células pluripotentes pré-hematopoiéticas ainda não haviam iniciado a expressão gênica de especialização. Entretanto, as CT da medula podem contribuir com o crescimento sob condições patológicas, como a observada fusão de células-tronco derivadas da medula óssea (BMDC) com células doentes em ratos com tirosinemia, onde os hepatócitos resultantes são funcionais (BORUE et al, 2004).

Além disso, esse mesmo grupo de pesquisadores induziu lesões profundas na pele de ratos e realizaram enxerto. Eles observaram a cicatrização, em tempos diferentes, e concluíram que o enxerto da BMDC, como células epiteliais, foi significantemente melhor do que no desenvolvimento natural da pele, tendo em vista os mesmos intervalos, propondo ainda um padrão para enxerto (BORUE et al, 2004).

Uma significante correlação entre as áreas conhecidas para serem de grande nível de divisão celular (alfa e beta) sugere que enxertos de BMDC devem ser preferencialmente realizados em regiões de alta proliferação. Essas células raramente se enxertam como células basais de citoqueratina-5 no epitélio folicular. Acredita-se que seja mais provável o enxerto de BMDC atuar 
como células transito-amplificatória do que como CT da pele. Os fatores de sinalização para migração dessas células ainda não são conhecidos. As células progenitoras ao entrar em contato com a área de ferimento podem se fundir com as células epidérmicas danosas, assumindo propriedades queratinócitas. De acordo com um trabalho não publicado (in put: Theise et al) em modelo de pele humana, são encontrados baixos níveis de SDF1 após os ferimentos, substância que recrutam BMDC para sobrevivência (BORUE et al, 2004).

Existem três células do compartimento que são constituídas pela sua ampla maturação: as intraorgânicas, as CT circulantes e CT extraorgânicas. Todas contribuem para a manutenção da integridade tecidual e a porcentagem de enxertamento indica as CT extraorgânicas com menor importância no reparo de ferimento na ausência de células, mobilizando fatores assim como G-CSF (BORUE et al, 2004).

\subsection{Células-tronco mesenquimais}

As pesquisas com características vitais e biológicas e potencial de diferenciação mostraram que quando comparadas com CTE, as células-tronco mesenquimais (CTM) têm um grau inferior de pluripotencialidade. A vida extensiva de CTE não é limitada, enquanto que a cinética de crescimento das CTM é gradualmente lenta, especialmente as somáticas. Existe uma busca por parte dos pesquisadores para encontrar CTM multipotentes, sem nenhuma limitação em sua expansão. Vários tecidos adultos e embrionários apresentam CTM, sendo derivadas, da medula óssea, do pâncreas fetal, do tecido adiposo e do cordão umbilical. Recentemente, pesquisadores realizaram grandes progressos para aplicações clínicas de CTM na terapia celular e gênica existindo ainda muitas perspectivas. Contudo, já é possível obter linhagens celulares de embriões entre quatro a sete semanas com características biológicas e potenciais do cultivo in vivo e in vitro. Elas mantêm os padrões de não diferenciação até a $40^{\mathrm{a}}$ passagem, não produzem antígenos CD 34 ou CD 45, sendo que OCT4 diminui com aumento do número de passagens (WU et al, 2006).

Segundo Wu e colaboradores (2006), as CTM cultivadas in vitro são capazes de se diferenciar em osteoblastos, condrócitos, adipócitos com gotí- 
gulas de lipídios ou apresentando ramificações. Realizando-se transfecç̧ão de EGF em hCTM, elas começaram a produzir queratina 19, EGF e caderina-E. Se o mesmo for feito com GPD, além de expressarem o gene, elas são capazes de se diferenciarem em folículos, grupos celulares, glândulas sudoríparas e tecidos subcutâneos, quando enxertadas (WU et al, 2006).

São necessários mais estudos para entender, em nível celular e molecular, o mecanismo de diferenciação das células mesenquimais. Sabe-se que Pax3 induz na interconversão de células mesenquimais em células epiteliais, o que pode auxiliar no processo da terapia gênica. Quando implantadas subcutaneamente em condições livres de patógenos, o número de folículos aumenta (WU et al, 2006).

Em outras pesquisas, as CTE diferenciam-se em células epiteliais. As transições epitelial-mesenquimal e mesenquimal-epitelial, que ocorrem durante o desenvolvimento embrionário, são importantes para a formação da epiderme e principalmente do tubo neural.

Contudo, de acordo com Wu e colaboradores (2006), as hCTM têm um grande potencial de diferenciação, com uma longa vida proliferativa, e podem se diferenciar em células da epiderme in vitro e in vivo.

\section{Conclusão}

Atualmente, ainda existe muita polêmica quanto às questões éticas, políticas e sociais em relação à utilização dessas células para aplicações terapêuticas. Apesar disso, muitas pesquisas já foram realizadas com muitos tipos de células-tronco existentes. As que foram revisadas por esse trabalho obtiveram resultados positivos para a regeneração epitelial da pele. Entretanto, são necessários maiores estudos em nível molecular para entender precisamente os fatores que influenciam a diferenciação das células-tronco em células epidermais. Acredita-se que dentro de alguns anos as técnicas existentes possam ser aperfeiçoadas e serem aplicadas como qualidade de recuperação tecidual de pacientes que apresentam problemas na epiderme. 


\section{Stem Cell capacity to skin epithelium regeneration}

\section{Abstract}

Skin is the first contact of body with environment and the first line of immunology protection. When injury occur and the skin loss the function, its stays expose to infection agents and begin a slow process of regeneration which cannot be complete because of the necessity and action of a lot activation factors. The difficulty is found because of presence of many different layers (epiderm, derm and subcutaneous tissue), cells and extracelular matrix. Ephitlelium (keratinocytes) marrow and mesenquimal stem cells show efficiency in the total skin recovery due to the employed of carpet cell of own patient. However, the process for differentiation cells it is not completely clear.

Key words: Skin. Injury. Regeneration. Stem cell.

\section{Referências}

ABREU, J. G.; ALMEIDA, K. L. Reprogramação celular: novas alternativas para terapia com células - tronco tiveram resultados promissores na UFRJ. Ciência Hoje, Rio de Janeiro, v. 38, n. 225, p.26-31, 2006.

ALONSO, L.; FUCHS; E. Stem cell of the skin epithelium. Proceedings of the National Academy of Sciences of the United States of America, United States, v. 100, p. 11830-11835, 2003.

BALDO, M. V. C. Somestesia. In: AIRES, M. M. Fisiologia. Rio de Janeiro: Guanabara Koogan, 1999. p. 217 - 230.

BELLINGHINI, R. H. Mocinha e bandida. Scientific American Brasil, São Paulo, n. 39, p. 80, 2005.

BOROJEVIC, R.; BALDUINO, A. Terapias Celulares e Bioengenharia Tecidual. In: MIR, L. (Org.). Genômica. São Paulo: Atheneu, 2004. p. 295-310.

BORUE, X. et al. Bone marrow-derived cells contribute to epithelial engraftment during wound healing. The American Journal of Pathology, United States, v. 165, n. 5, p. 1767-1772, 2004. 
BRAGA, J. Liderança no coração. Scientific American Brasil, São Paulo, n. 39, p. 74-79, 2005.

CARVAlHO, A. C. C. Células-tronco é promessa para medicina do futuro. Ciência Hoje, Rio de Janeiro, v. 29, n. 172, 2001.

CARvalHO, A. C. C. Células - tronco: A medicina do futuro. Disponível em: $<$ http://www.educacaopublica.rj.gov.br/biblioteca/biologia/bio10d.htm >. Acesso em: 25 set. 2006.

CLARKE, M. F.; BECKER, M. W. O potencial maligno das células - tronco. Scientific American Brasil, São Paulo, v. 51, p 39-46, 2006.

FRANCO, V. O. O uso de células-tronco na regeneração do miocárdio. 2006. 27 p. Monografia de graduação, Centro Universitáio de Brasília -UniCEUB, Brasília, 2006.

GENESER, F. Histologia. 3. ed. Rio de Janeiro: Guanabara Koogan, 2003. 616 p.

GIBBS, W. W. O genoma oculto. Scientific american Brasil, São Paulo, v. 19, p. 52-59, 2003.

GIBBS, W. W. O genoma oculto além do DNA. Scientific american Brasil, São Paulo, v. 20, p. 82-89, 2004.

GOWDAK, L. H. W. Terapia celular em cardiologia. Disponível em: <http://www. comciencia.br/reportagens/celaulas/12.shtml>. Acesso em: 30 jul. 2006.

IGUMA, L. T. Clonagem Bovina por transferência nuclear de células somáticas: efeitos da transfecção de células doadoras de núcleo e do FSH em ovócitos receptores. 2005. 234 f. Tese de Doutorado - Instituto de Ciências Biológicas, Departamento de Biologia Molecular, Universidade de Brasília, Brasília, 2005.

JUNQUEIRA, L. C.; CARNEIRO, J. Histologia básica. 10. ed. Rio de Janeiro: Guanabara Koogan, 2004.

KANG, Y.K. et al. Aberrant methylation of donor genome in cloned bovine embryos. Nature Genetics, United States, v. 28, p.173-177, 2001.

KUTCHAI, H. C. Fisiologia celular. In: BERNE, R. M. Fisiologia. 4. ed. Rio de Janeiro: Guanabara Koogan, 2000. p. 3 -19. 
LANGDON; R. C. Using Cultured Keratinocytes for Treating Burns. The Western Journal of Medicine, United States, v. 151, p. 655, 1989.

LANZA, R.; ROSENTHAL, N. Células-tronco: obstáculos no caminho que leva da promessa terapêutica aos tratamentos reais em seres humanos. Scientific American Brasil, São Paulo, v. 26, 2004.

LI, A. et al. Extensive tissue regenerative capacity of neonatal human keratinocyte stem cell and their progeny. The Journal of Clinical Investigation, United States, v. 113, p. 390-400, 2004.

LIANG, G. et al. Identification ofDNA methylation differences during tumorigenesis by methylation-sensitive arbitrarily primed polymerase chain reaction. Methods, San Diego, n. 27, p.150-155, 2002.

MANOELI, B. C. N. O uso de células-tronco no tratamento do diabetes mellitus tipo I. 2006. 37 p. Monografia de graduação, Centro Universitário de Brasília UniCEUB, 2006.

MOORE; K. K.; PERSAUD; T. V. N. Embriologia básica. 5. ed. Rio de Janeiro: Guanabara Koogan, 2000. 451 p.

OKAMOTO, O. K.; MOREIRA FILHO, C. A. Células-Tronco: genômica funcional e aplicações terapêuticas. In: MIR, L. (org.). Genômica. São Paulo: Atheneu, 2004. p. 311-327.

PEREIRA, A. Regeneração pioneira do músculo cardíaco. Ciência hoje. 2001. Disponível em: < http://cienciahoje.uol.com.br/3089 >. Acesso em: 11 nov. 2005.

PEREIRA, L. V. Clonagem terapêutica... e polêmica. Disponível em: <http:// www.comciencia.br/reportagens/celulas/10.shtml>. Acesso em: 10 mar. 2006.

ROSS; M. H.; ROMRELL; Histologia texto e Atlas. 2. ed. São Paulo: Editorial médica panamericana, 1993.

SEGRE, M. A propósito da utilização de células-tronco. 2004. Disponível em: $<$ http://www.comciencia.br/reportagens/celulas/11.shtml $>$. Acesso em: 11 jun. 2006.

SHAFER, J. A. Regulação da temperatura corporal. In: JOHNSON, L. R. (Ed.) Fundamentos de fisiologia médica. 2. ed. Rio de Janeiro: Guanabara Koogan, 2000. p. 681-689. 
STEVENS, A.; LOWE, J. Histologia Humana. 1. ed. São Paulo: Manole, 2001.

TORTORA; GRABOWSKI. Princípios de anatomia e fisiologia. 9. ed. Rio de Janeiro: Guanabara Koogan, 2002.

VERJOVSKY, M. Células-tronco adultas que se comportam como embrionárias podem derrubar obstáculo à pesquisa. 2006. Disponível em: <http://cienciahoje. uol.com.br/4327>. Acesso em: 17 ago. 2006.

WEISS, R. O poder de se dividir. National Geographic Brasil, São Paulo, v. 64, p 45-69, jul. 2005.

WU, M. et al. Differentiation potential of human embryonic mesenchymal stem cells for skin-related tissue. British Journal of Dermatology, Nottingham, UK, v. 155, p. 282-291, 2006.

ZATZ, M. Célula-tronco. Disponível em: <http://www.drauziovarella.com.br/ entrevistas/celulastronco.asp>. Acesso em: 10 abr. 2006.

ZATZ, M. Clonagem e células-tronco. Revista estudos avançados, São Paulo, v. 51, n. 18, 247-256. 2004.

ZAGO, M. A. Terapia com células-tronco pode causar câncer. Scientific American Brasil, São Paulo, v. 51, p. 45, 2006. 